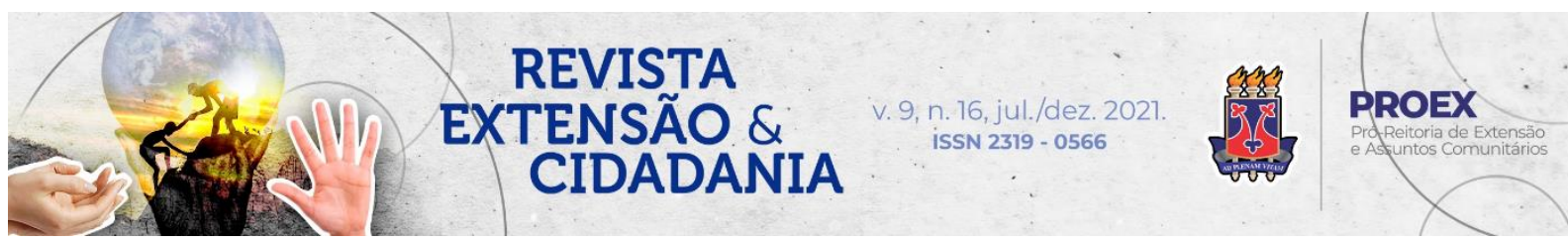

DOI: $10.22481 /$ recuesb.v9i16.9193

\title{
CURRICULARIZAÇÃO DA EXTENSÃO UNIVERSITÁRIA: RELATO DE UMA EXPERIÊNCIA NUM CURSO DE ENGENHARIA DE TRANSPORTES
}

\author{
CURRICULARIZATION OF UNIVERSITY EXPTENSION: REPORT OF AN \\ EXPERIENCE IN A TRANSPORT ENGINEERING COURSE OF UFG
}

\section{CURRICULARIZACIÓN DE AMPLIACIÓN UNIVERSITARIA: INFORME DE UNA EXPERIENCIA EN UN CURSO DE INGENIERÍA DE TRANSPORTE}

\begin{abstract}
Alex Mota dos Santos ${ }^{1}$
Resumo: O objetivo deste relato é apresentar uma experiência da curricularização da extensão universitária num curso de Engenharia de Transportes sob a perspectiva da educação para o trânsito. A metodologia contemplou a realização de atividades de reflexões teóricas e práticas em escolas em conjunto com a comunidade do entorno da Universidade Federal de Goiás, campus da cidade de Aparecida de Goiânia, estado de Goiás. Os resultados revelaram uma experiência de curricularização da extensão num curso de engenharia. Ademais, as atividades de vivência das questões relacionadas ao trânsito foram bem avaliadas pelos estudantes, além disso, contribuiu, na visão dos mesmos, para que pensassem de forma autônoma, a partir do conhecimento construído as várias mãos, por meio das ações de extensão e pesquisas empíricas. Palavras-chave: Educação para o trânsito. Ensino. Educação continuada.

Abstract: The objective of the report is to present an experience of the curricularization of university extension in a transport engineering course from the perspective of traffic education. The methodology included carrying out activities of theoretical reflections and practical activities in schools and with the community of the Federal University of Goiás, campus of the city of Aparecida de Goiânia, State of Goiás. The results revealed an experience of curriculum extension in a course of engineering. Moreover, as activities related to traffic-related issues have been well evaluated by the students. In addition, it contributed, in their view, to think automatically from the knowledge built in several hands, through extension actions and empirical research.
\end{abstract}

Keywords: Traffic education. Teaching. Continuing education.

Resumen: El objetivo del informe es presentar una experiencia de la curricularización de la extensión universitaria en un curso de ingeniería del transporte desde la perspectiva de la educación vial. La metodología incluyó la realización de actividades de reflexión teórica y prácticas en las escuelas y con la comunidad alrededor de la Universidad Federal de Goiás, campus de la ciudad de Aparecida de Goiânia, estado de Goiás. Los resultados revelaron una

\footnotetext{
${ }^{1}$ Doutor em Geografia. Docente da Universidade Federal de Goiás, campus de Aparecida de Goiânia, Goiás, Brasil. Orcid: https://orcid.org/0000-0002-5156-3968 E-mail: alex.geotecnologias@ gmail.com
} 
experiencia de extensión curricular en un curso de Ingeniería. Además, las actividades de experimentar problemas relacionados con el tráfico fueron bien evaluadas por los estudiantes. Además, contribuyó, en su opinión, a pensar de forma autónoma a partir del conocimiento construido en diferentes manos, a través de acciones de extensión e investigación empírica.

Palavras-chaves: Educación en Tránsito. Enseñando. Educación contínua.

\section{Introdução}

As recomendações para a implementação da extensão na educação superior brasileira não são recentes, datam da Lei de Diretrizes e Bases da Educação Nacional - Lei nº 4.024/1961 (BRASIL, 1961). Além disso, por meio do Plano Nacional de Educação - PNE 2001-2010 (Lei Federal $n^{\circ}$ 10.172/2001) (BRASIL, 2001), em sua Meta 23, ficou estabelecida a reserva mínima de dez por cento do total de créditos exigidos para integralização da graduação, cumpridos pelos estudantes em atividades de extensão. Apesar disso, tais recomendações foram ignoradas nos cursos superiores, mesmo àqueles criados pelo Programa de Reestruturação e Expansão das Universidades Federais (REUNI).

A partir do PNE, Lei 13.005, de 25 de junho de 2014 (BRASIL, 2014) foi retomada a exigência da curricularização da extensão nos cursos superiores no Brasil. Contudo, somente no ano de 2018, que se estipulou um prazo para que, no mínimo, $10 \%$ (dez por cento) do total da carga horária curricular dos estudantes das graduações fossem realizadas na forma de ação de extensão. Assim, o Conselho Nacional de Educação (BRASIL, 2018) estabeleceu o prazo de 3 (três) anos, a contar da data de sua homologação, em 18 de dezembro de 2018, para que as instituições de ensino superior incorporem a extensão na matriz curricular dos cursos.

Como resultado dessas recomendações, observou-se, mesmo que, de forma isolada, algumas ações concretas de curricularização da extensão nos cursos de graduação. Nesse sentido, Coelho (2017) apresenta a experiência da Universidade Federal do Rio de Janeiro (UFRJ) e da Universidade Federal da Bahia (UFBA).

Além disso, a partir do conhecimento da experiência de outras instituições, observou-se a efetivação da curricularização das atividades de extensão em alguns cursos da Universidade Federal de Santa Maria (UFSM) e do Instituto Federal de Santa Catarina (IFSC). Essa realidade, inclusive nos cursos de Engenharia, motivou a realização de uma experiência de curricularização da extensão no curso de Engenharia de Transportes, da Universidade Federal de Goiás (UFG), como parte das discussões para curricularização da extensão, a partir da

Revista Extensão \& Cidadania, v. 9, n. 16, p. 136-152, jul./dez. 2021. 
reestruturação do Projeto Pedagógico do Curso $(\mathrm{PPC})^{2}$ que está em discussão para reformulação.

A discussão no curso de Engenharia de Transportes se iniciou na reunião do Núcleo Docente Estruturante (NDE) do mês de junho do ano de 2019. Nesse mesmo período, o curso propôs o projeto de extensão "Ações na escola para educação e segurança no trânsito" que teve início em agosto de 2019, com duração de 12 meses e foi financiado pela Pró-Reitoria de Extensão e Cultura (PROEC-UFG).

A partir do projeto aprovado e da observação da disciplina Trânsito e Educação, concluiu-se que estavam criadas todas as condições para a realização da experiência que é apresentada neste artigo. Ou seja, a curricularização por meio da integração do ensino, da extensão e da pesquisa num curso de Engenharia de Transportes.

\section{Metodologia}

A experiência da curricularização das atividades de extensão no curso de Engenharia de Transportes, da UFG, foi pensada a partir da disciplina Trânsito e Educação. Contudo, a reflexão e até proposta para outras disciplinas foi apresentada ao NDE do referido curso, após participação no I Seminário sobre Curricularização da Extensão Universitária, realizado no mês de junho de 2019, pela UFG.

A experiência ocorreu por meio do projeto de extensão "Ações na Escola para Educação e Segurança no Trânsito", que concorreu ao edital da PROEC-UFG no ano 2019/2020. O projeto foi contemplado com bolsa atribuída a um estudante do curso de Engenharia de Transportes. Além disso, 16 dos 18 professores que atuam no curso participaram das ações do projeto.

A disciplina Trânsito e Educação é optativa no PPC do curso Engenharia de Transportes, da UFG, nunca foi ofertada desde a implantação do mesmo no ano de 2015. Assim, para o segundo semestre de 2019, foi elaborado o primeiro plano de aula conforme ementa que consta na matriz curricular do curso e 29 estudantes se matricularam para cursar a disciplina, divididos em seis grupos.

\footnotetext{
${ }^{2}$ Projeto Pedagógico do Curso de Engenharia de Transportes, da Universidade Federal de Goiás. Disponível em: https://files.cercomp.ufg.br/weby/up/767/o/PPC-ET_1a-Rev_Aprovado_Camaras.pdf. Acesso em: 26 mar. 2020.
}

Revista Extensão \& Cidadania, v. 9, n. 16, p. 136-152, jul./dez. 2021. 
A realização da disciplina foi organizada em etapas, conforme a matriz curricular, sendo a primeira, composta por cinco aulas em que se discutiu os aspectos teóricos para pensar a educação para o trânsito (quadro institucional; legislação; atribuições e gestão) e os fundamentos da educação de trânsito (matrizes conceituais e ideias correlacionadas). $\mathrm{Na}$ segunda etapa, foram apresentados os objetivos e públicos-alvo da educação de trânsito particularidades, métodos e técnicas e educação de trânsito em diferentes contextos: órgão gestores de transporte/trânsito; escolas; setor saúde; centros de formação de condutores e empresas.

As ações de extensão foram alocadas na segunda etapa da disciplina em que se realizou atividades junto à comunidade. A recomendação era para que as atividades seguissem o que preconiza a Política Nacional de Extensão Universitária (2012, p. 15), em que “a Extensão é uma via de mão-dupla, com trânsito assegurado à comunidade acadêmica, que encontrará, na sociedade, a oportunidade de elaboração das práxis de um conhecimento acadêmico". Além disso, que a universidade, no texto representada pelos estudantes, absorva os conhecimentos sobre e da sociedade externa à instituição.

$\mathrm{Na}$ segunda etapa, os estudantes elaboraram e apresentaram planos de trabalho de atuação junto à comunidade. Os planos obrigatoriamente tinham que apresentar uma breve descrição, objetivo, seguindo a proposta apresentada por Lima (2009). De forma que esta autora classificou as atividades de educação para o trânsito, de acordo com o foco em: legislação/infrações; dados estatísticos; mortalidade e morbidade; socialização e acessibilidade e mobilidade sustentável. Na perspectiva do estilo, a pesquisadora revelou que as campanhas podem ser: chocante; poética positiva; cômico; emotivo; informativo; mobilizador e infantil (LIMA, 2009). No que se refere ao público, ela destaca: motoristas em geral; pedestres; motociclistas; taxistas (motoristas por aplicativos); motoristas de caminhões/ônibus; condutores do transporte escolar; crianças, jovens, idosos e passageiros em geral; e sobre o meio indica: televisão; rádio; imprensa; corpo-a-corpo; intervenção artística; palestra; internet e alternativos (LIMA, 2009).

Em síntese, os planos valeram de metodologias variadas, dentre as quais, jogos obtidos de materiais didáticos existentes; estudo da percepção a partir do uso dos mapas mentais e observações participantes; criação de mídias, e um diagnóstico das escolas públicas estaduais da cidade de Goiânia. Nessa última análise, empregou-se o uso de questionário, instrumentos amplamente aplicados em extensão e pesquisa. Segundo Chaer et al. (2011, p. 251), "o

Revista Extensão \& Cidadania, v. 9, n. 16, p. 136-152, jul./dez. 2021. 
questionário é uma técnica bastante viável e pertinente para ser empregada quando se trata de problemas cujos objetos de pesquisa correspondem a questões de cunho empírico, envolvendo opinião, percepção, posicionamento e preferências dos pesquisados".

O estudo de percepção envolveu também a produção de mapas mentais, que têm sido utilizados para aquisição de dados e informações para a extensão e pesquisa (SANTOS et al., 2018; SANTOS, 2019; SANTOS et al., 2020).

Após apresentação e aprovação dos planos de ação, os estudantes partiram para etapas práticas. A recomendação foi para que as atividades ocorressem no horário da disciplina, de modo a não comprometer a participação dos estudantes nas outras disciplinas do curso de Engenharia de Transportes, que é integral.

Os trabalhos realizados pelos estudantes foram apresentados e avaliados em duas aulas, realizadas na forma de seminários. Após a conclusão da disciplina, foi apresentado aos estudantes, matriculados na disciplina, um instrumento de coleta de dados para investigar suas percepções sobre o modo como a disciplina foi conduzida. Além disso, observou-se a avaliação institucional realizada em todos os semestres pela UFG para todas as disciplinas.

O instrumento de avaliação apresentado pelo professor da disciplina foi composto por 13 questões, sendo 10 fechadas e 3 abertas. As perguntas abertas versavam sobre a satisfação com a disciplina cursada. A estruturação do questionário seguiu a proposta apresentada no trabalho de Chaer et al. (2011).

A avaliação das atividades de extensão é etapa extremamente importante e recomendada pela Política Nacional de Extensão Universitária (2012), pois é necessário averiguar o impacto das ações. Segundo Santos et al. (2020), essa etapa deve ser contínua, processada no decorrer das atividades; ser qualitativa e quantitativa, realizada pela universidade e pelo grupo atingido pelas ações. Assim, a avaliação neste texto se restringe à prática da disciplina como um todo, ou seja, não serão apresentadas as avaliações de cada ação desenvolvida pelos estudantes. Por fim, na segunda etapa já foi possível a definição das escolas atendidas pelo projeto.

\section{Resultados e discussões}

As reflexões teóricas revelaram que a educação para o trânsito deve partir de um princípio básico, que há "um equívoco quando associamos o trânsito exclusivamente aos deslocamentos de veículos, pois as pessoas 'vestem' um modo de transporte para suprir a

Revista Extensão \& Cidadania, v. 9, n. 16, p. 136-152, jul./dez. 2021. 
necessidade de locomoção" (SANTOS, 2005, p. 19). Ou seja, foi necessário situar qual o conceito de trânsito que conduziria as atividades. Além disso, situou-se as atividades nas três perspectivas de análise do trânsito, a via, o veículo e o homem (ROZESTRATEN, 1998), acrescentou-se, assim, a preocupação com os animais, principalmente os domésticos.

Avançou-se, a partir dos fundamentos da sociologia, para pensar que os conflitos no trânsito, em certa medida, são consequências das relações que estão estabelecidas na sociedade brasileira (MAOSKI, 2015), especialmente no que se refere à confusão entre público e privado, que leva a embates quanto ao uso de espaços públicos, como as ruas.

Assim, a discussão sobre trânsito envolve, ainda, a engenharia, o esforço legal e a educação, o equilíbrio entre essas três vertentes é importante, pois são interdependentes. A engenharia, que envolve um conjunto de conhecimento já iniciado pelos estudantes do curso de graduação em Engenharia de Transportes, é a área responsável pelo projeto, construção, sinalização e manutenção das vias urbanas e rurais; o esforço legal é a área responsável pelo policiamento, fiscalização, autuação de infratores e aplicação de penalidades de trânsito e, por último, a educação é a área para formação e conscientização de todos os usuários do trânsito, pedestres e condutores de veículos.

Neste sentido, estabeleceu-se algumas questões geradoras dos debates em sala de aula, dentre os quais tem-se: podemos educar a via? Podemos educar a Lei? Podemos educar o veículo? Podemos educar as pessoas? Com efeito, qual a "melhor" faixa etária para apresentar a educação para o trânsito?

Sobre as três primeiras questões ficou evidente que a educação só seria possível quando oferecida às pessoas. Sobre a idade, e comparando o desempenho de tarefas de adolescentes com idades entre 15 e 16, 18 e 20 anos, a pesquisa de Glendon (2011) revelou maior amplitude na atividade do córtex cingulado anterior entre o grupo mais velho. Segundo o autor, a região do córtex, associada a erros de desempenho e automonitoramento, mostrou-se mais madura nos jovens com mais idade (GLENDON, 2011). Segundo o autor, condutores mais novos têm características comportamentais diferentes dos motoristas com mais idade, pois os adolescentes tendem a pensar pouco sobre as consequências de suas ações e menos a longo prazo, focando nos efeitos imediatos. Podem responder, também, de forma mais emocional que o adulto, sendo suscetível às provocações e a agressões e são propensos a agir de forma mais lenta ao medo que o adulto, o que faz terem mais dificuldade em identificar situações de risco (GLENDON, 2011).

Revista Extensão \& Cidadania, v. 9, n. 16, p. 136-152, jul./dez. 2021. 
Portanto, concorda-se que a educação nas primeiras fases da vida escolar pode ser mais eficiente, e foi nessa faixa etária que decidiu-se atuar com mais afinco. A partir de tais considerações da faixa etária mais adequada na perspectiva de Glendon (2011), reforçou-se as atividades para crianças e adolescentes em três escolas públicas localizadas nas proximidades da UFG. Além disso, Martins (2004) defende que crianças e jovens estão mais abertos ao aprendizado de novas condutas.

Os temas definidos pelos grupos foram: elaboração de material informativo - i: cartilha para uso em escolas; difusão do conhecimento sobre o trânsito para crianças do ensino fundamental - ii: oficinas e jogos interativos; iii: análise da percepção de crianças sobre mobilidade em espaços urbanos; produção audiovisual sobre itens de segurança em veículos para uso das crianças e cuidados com animais domésticos nas ruas; iv: criação de uma mídia social para divulgação dos cuidados do uso da bicicleta em cidades; v: diagnósticos de escolas públicas estaduais da cidade de Goiânia sobre os conhecimento da escola a respeito do trânsito no entorno das escolas; vi: criação de um vídeo para tratar dos cuidados necessários com animais em situação de rua e o transporte de criança.

De forma geral, as atividades proporcionaram a autonomia na construção do conhecimento e relação com a comunidade envolvida. Da primeira possibilidade, observou-se que os estudantes mergulharam nos temas estudados com entusiasmo, pois a realização era da responsabilidade deles. Essa avaliação, que é subjetiva e não estruturada, foi importante e realizada ao longo do semestre, os alunos superaram os estudos pela reprodução, e passaram para uma fase de produção inédita de seus materiais.

Um dos grupos realizou a estruturação de uma cartilha, o documento explora o papel de todos os envolvidos no trânsito (condutores de veículos, de motocicletas, os passageiros, ciclistas, pedestres) e apresenta um panorama geral dos acidentes no país e os aspectos gerais da sinalização. Este documento está disponível para downloads pelas escolas no site do curso de Engenharia de Transportes. A avaliação do material foi realizada pelos professores do referido curso, que também participaram do projeto. A variedade de cores e a linguagem acessível foram observados no material que tem como usuários, crianças e adolescentes.

As oficinas e jogos foram realizadas semanalmente em duas escolas: Escola Jesus Conceição Leal (Figura 1) e Escola Municipal Espansul. Uma das oficinas ministradas tratou sobre a tomada de decisão no trânsito, a observação dos obstáculos e todos os cuidados necessários para os deslocamentos seguros. Para auxílio nessa atividade, a professora do curso

Revista Extensão \& Cidadania, v. 9, n. 16, p. 136-152, jul./dez. 2021. 
de Engenharia de Transportes, responsável pela disciplina Logística, levou jogos analógicos, ou seja, impressos em papel.

\section{Figura 1 - Circuito de trânsito para o ensino fundamental na Escola Jesus Conceição}

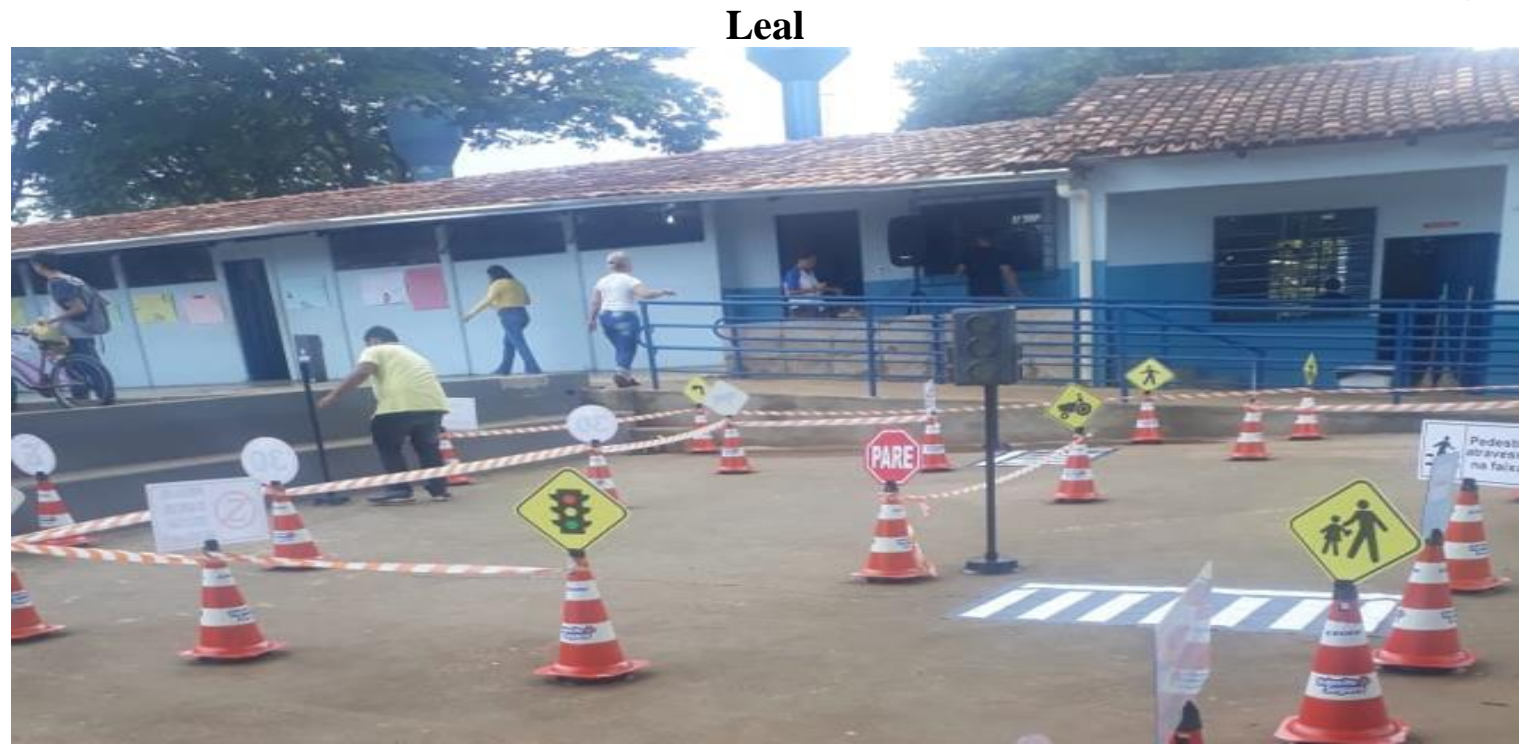

Fonte: Elaborado pelo autor.

Esses jogos ofereciam possibilidade de diversos caminhos, mas as crianças foram incentivadas a escolher o caminho mais adequado, conforme proposta das atividades, num esforço pela tomada de decisão a partir da "roteirização analógica" e àquela 'impressa' no pátio da Escola Jesus Conceição Leal. Utilizou-se a estrutura da escola de trânsito adquirida pelo curso de Engenharia de Transportes, esses equipamentos permitem simular situações reais no trânsito.

As atividades na Escola Municipal Espansul revelaram ainda o conhecimento sobre sinalização, o uso adequado da bicicleta e comportamentos de risco no trânsito. Os resultados dessas atividades foram apresentados em forma de artigo no texto intitulado "Trânsito e educação: relato de uma experiência no ensino fundamental, no município de Aparecida de Goiânia, Goiás", de autoria de parte dos estudantes matriculados na disciplina (SOUSA et al., 2020).

Um outro grupo realizou atividades na Escola Municipal Professora Vinovita, trabalho intitulado "A criança e o espaço urbano". Essa escola é de regime integral e, no segundo semestre de 2019, estavam matriculados 427 alunos e alunas, distribuídos entre o $1^{\circ}$ ao $5^{\circ}$ ano. A partir dessa prática, os estudantes da disciplina Trânsito e Educação elaboraram a análise da

Revista Extensão \& Cidadania, v. 9, n. 16, p. 136-152, jul./dez. 2021. 
percepção do caminho e do trânsito da casa até a escola. A compreensão do caminho de casa até a escola foi complementada a partir da elaboração de mapas mentais por parte das crianças. Segundo Santos et al. (2020), os mapas mentais proporcionam a produção de conhecimento de forma autônoma pelas crianças. Por ser uma atividade lúdica, a prática revelou que é uma atividade bem aceita pelos mais jovens e valoriza sua autonomia no processo de ensino e aprendizagem.

Assim, foi observado que os estudantes menores se deslocam predominantemente no transporte individual, carro. As maiores, do terceiro, quarto e quinto ano, deslocam em vans. Esse resultado se deve ao fato de que a escola se encontra isolada na paisagem da cidade de Aparecida de Goiânia. Além disso, com base nos resultados obtidos, foi possível concluir: as crianças que vão de carro, têm uma visão de espaço e de localização limitadas, numa comparação com as que vão a pé ou de bicicleta. As crianças mais velhas tendem a não desenhar sobre o espaço ou sobre o trânsito, pois observam prédios públicos e comerciais.

Foi observado em campo que a Escola Municipal Professora Vinovita, apesar de pública, oferece ensino de qualidade, estrutura completa e, por isso, é 'disputada' por pais e mães todos os anos. Todo o quadro docente incentiva e aceita projetos de extensão nas dependências da escola e isso já foi relatado em Santos et al. (2018). Por ser afastada dos bairros mais periféricos, a escola é acessada, na maioria, por pessoas que possuem veículos individuais.

A criação da mídia social (Figura 2) objetivou a divulgação dos cuidados do uso da bicicleta em grandes cidades, como Goiânia, exemplo do caso de estudo. Os estudantes criaram um roteiro destinado a quem usa a bicicleta para o lazer, visitaram parques da cidade num trabalho próximo aos usuários.

Revista Extensão \& Cidadania, v. 9, n. 16, p. 136-152, jul./dez. 2021. 
Figura 2 - Aspecto da página @compartilhemobilidade no Instagram

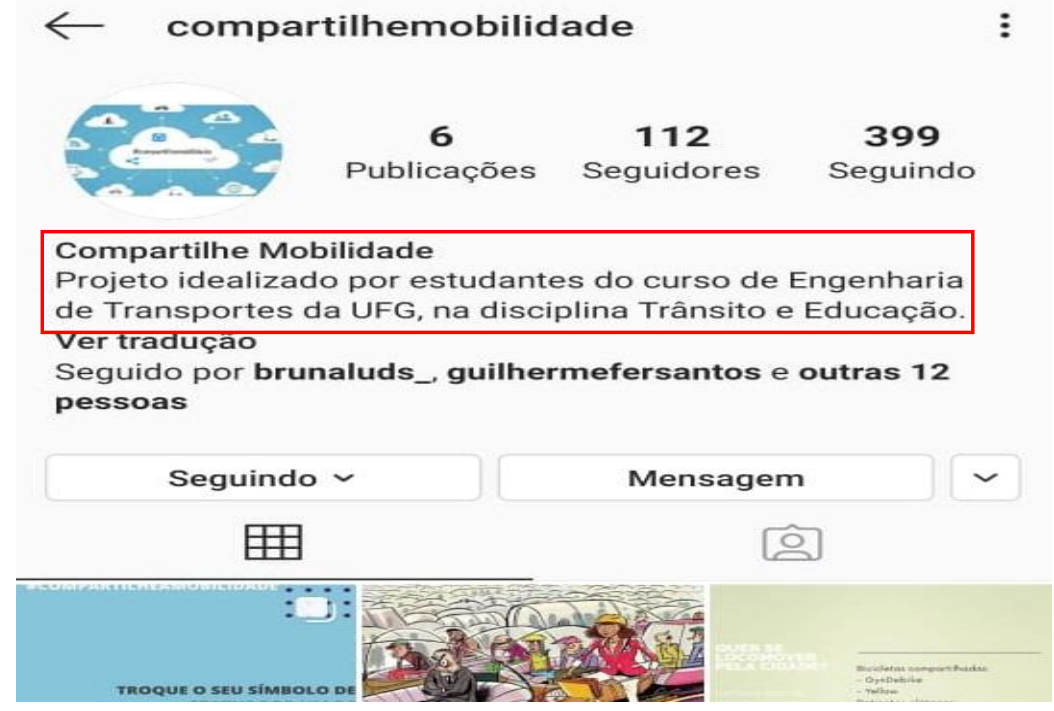

Fonte: @compartilhemobilidade.

Outras mídias foram criadas e publicadas no Instagram do curso de Engenharia de Transportes, @divulgaengtransporteufg no. Destaque aos vídeos que tratam sobre os prejuízos causados pelo uso do celular no trânsito, na Figura 3, e os 10 cuidados para se ter em viagens de carro com crianças, conforme Figura 4.

Figura 3 - Aspecto do vídeo “Os 4 principais prejuízos causados pelo uso de celular no trânsito"

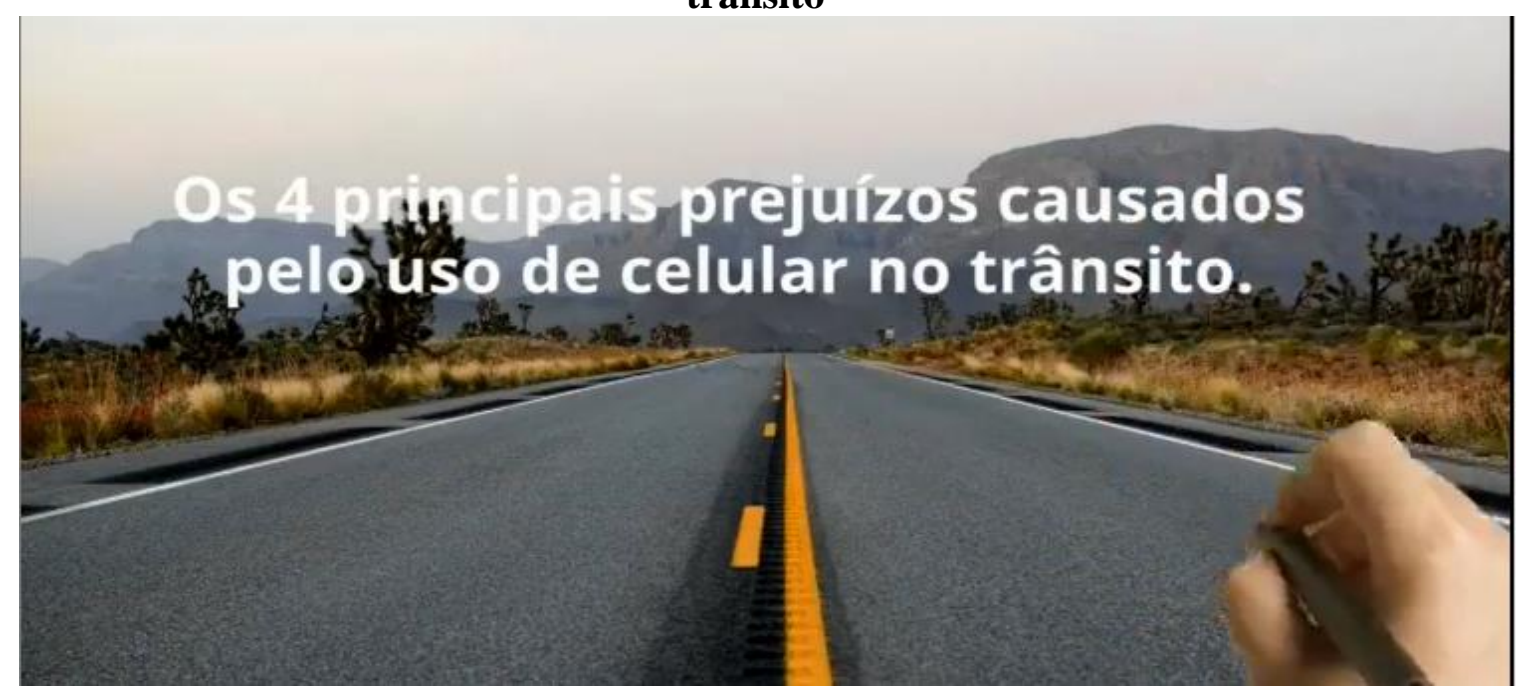

Fonte: @ divulgaengtransporteufg.

Revista Extensão \& Cidadania, v. 9, n. 16, p. 136-152, jul./dez. 2021.

ISSN 2319-0566 DOI: 10.22481/recuesb.v9i16.9193 
Figura 4 - Aspecto do vídeo "Os 4 principais prejuízos causados pelo uso de celular no trânsito"

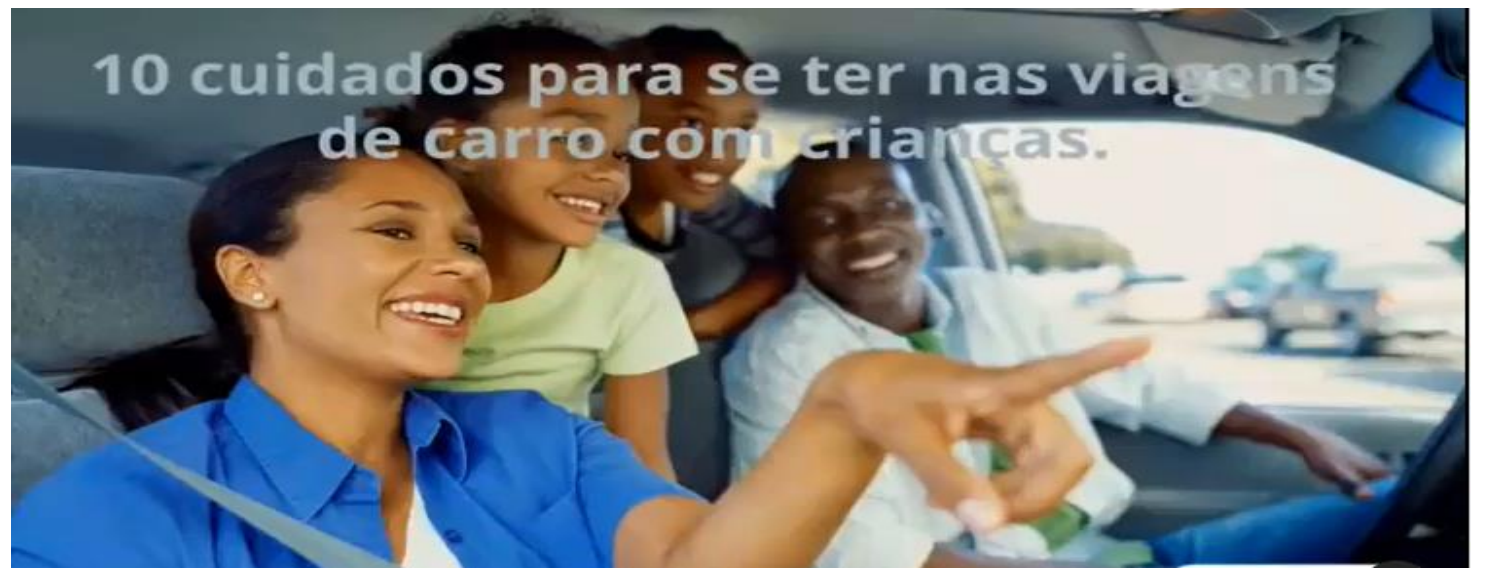

Fonte: @divulgaengtransporteufg.

Outra análise desenvolvida foi uma pesquisa básica sobre o conhecimento que as escolas possuem a respeito do trânsito no seu entorno. Os estudantes desse grupo se valeram de um questionário que foi encaminhado via e-mail para as escolas estaduais localizadas na cidade de Goiânia. O instrumento de coleta de dados, com 12 perguntas, foi enviado para os e-mails de 119 instituições de ensino, dentre as quais, 23 responderam ao questionário.

Do relatório dos estudantes destaca-se que, apropriados para avaliação da ação de extensão, “As discussões a respeito do trânsito, principalmente nos grandes centros urbanos, têm ganhado um cenário de destaque, já que este vem interferindo de forma relevante na vida dos indivíduos, seja na perda de tempo ou no que se refere a segurança de locomoção”. Assim, $52,2 \%$ das escolas ofereciam o ensino fundamental e médio e 56,5\% consideraram "muito importante" o ensino da educação para o trânsito, contudo também 56,5\% relataram não ministrar educação para o trânsito nas disciplinas do currículo. Das escolas que responderam realizar a educação para o trânsito, metade delas informou que esse ensino era ministrado na forma de eventos (palestras, workshop, passeios ciclísticos, caminhadas), ou seja, não é de forma contínua.

Das escolas que informaram não ministrar Educação para o Trânsito, 46,2\% revelou que faltam profissionais qualificados para esse fim. De acordo com os resultados, em 18 escolas (78,3\%), há a presença das faixas de pedestres, um dispositivo de sinalização muito importante nesse local, visto que grande parte dos alunos são pedestres na maior parte do tempo.

Revista Extensão \& Cidadania, v. 9, n. 16, p. 136-152, jul./dez. 2021. 
Outro aspecto observado foi sobre a acessibilidade para cadeirantes. Esse dado foi revelador, pois como se sabe há legislação específica que obriga essas obras em escolas, contudo, apenas $52,2 \%$ possuíam rampas, por exemplo.

Os estudantes perguntaram ainda de quem é a responsabilidade pelo ensino de trânsito na escola, a maioria das escolas, 56,5\%, respondeu que a responsabilidade é dos órgãos públicos, 30,4\% indicaram que esse é um de todos. Os estudantes observaram que ainda há uma visão muito restrita sobre o tema, sendo que as escolas deveriam ser as principais disseminadoras desses conhecimentos.

A partir dos dados, os estudantes concluíram que é necessária a conscientização dos profissionais da educação sobre o Ensino de Trânsito nas escolas de Ensino Fundamental e Médio. Assim, é conveniente, diante do cenário observado pelos estudantes, a regulação de um material exclusivo para este assunto. É necessário, ainda, o treinamento continuado de profissionais da área da educação para o ensino do trânsito na escola, apesar da fiscalização existente, são necessárias ações de melhoria da sinalização e, por fim, assegurar a acessibilidade daqueles com dificuldade motora.

O último grupo estruturou dois vídeos para tratar dos cuidados necessários com animais em situação de rua e o transporte de crianças. O primeiro vídeo traz informações sobre cuidados com cães em situação de rua, e também atenção aos passeios, mostra, por exemplo, os tipos de coleiras mais adequadas. O vídeo para transporte das crianças focou no uso da cadeirinha e do cinto de segurança, os principais tipos disponíveis no mercado.

Esses materiais também estão disponíveis no site do curso de Engenharia de Transportes, e seu uso será incentivado nas escolas através de visitas da equipe do projeto de extensão “Ações na escola para educação e segurança no trânsito". Nesse sentido, destaca-se a estruturação do $e$-book (Figura 5) intitulado também por "Ações na escola para educação e segurança no trânsito", composto por 10 capítulos, assinados por estudantes e professores do curso de Engenharia de Transportes da UFG. O link para acesso ao e-book: $<$ https://transportes.fct.ufg.br/p/32107-publicacoes $>$.

Revista Extensão \& Cidadania, v. 9, n. 16, p. 136-152, jul./dez. 2021. 
Figura 5 - Aspecto do e-book (capa e contracapa) "Ações na escola para Educação e Segurança no Trânsito"
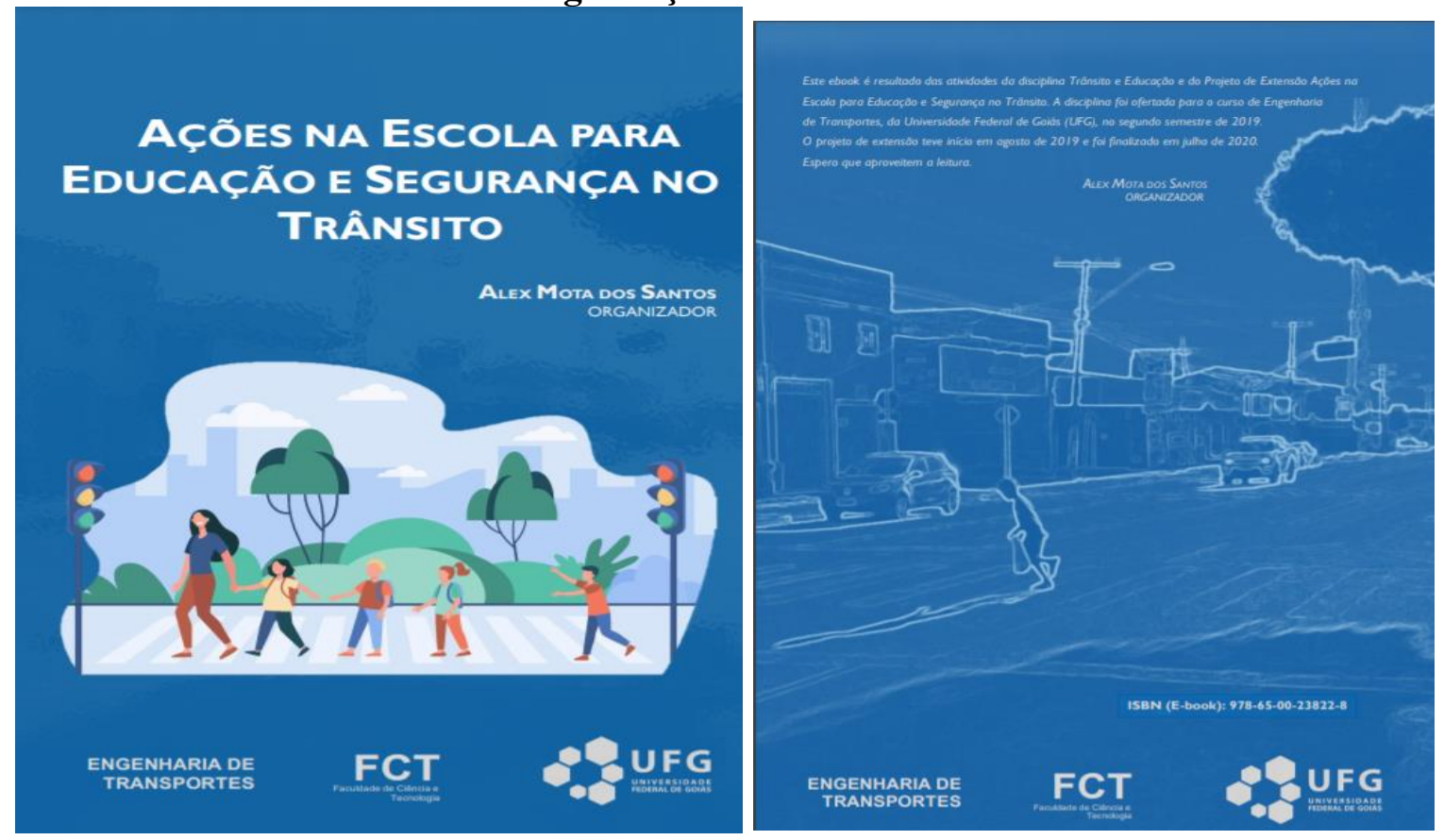

Fonte: Santos (2021).

Sobre segurança viária para crianças, explorou-se dados de uma Organização Não Governamental (ONG) - ONG Criança Segura ${ }^{3}$. Segundo estas informações, a redução do número de acidentes que resultaram em óbitos foi constante desde o ano de 2001. Conforme Campos e Raia Junior (2013, p. 3), “está ocorrendo uma queda consistente em números absolutos e taxas de acidentalidade de trânsito de crianças de 0 a 14 anos. $\mathrm{O}$ uso da cadeira de assento, sem dúvida, contribuiu para esse cenário".

Além dos temas apresentados, foram realizadas ações em parceria com a Secretaria Executiva de Mobilidade e Trânsito (SMTA) e com o Departamento Estadual de Trânsito de Goiás (DETRAN-GO), no âmbito da Semana Nacional de Trânsito, ocorrida em de 18 a 25 de setembro de 2019. Na ocasião, foi lançada a campanha proposta por um dos estudantes matriculados no curso de Engenharia de transportes (Figura 6). A campanha foi divulgada nas escolas e nas redes sociais do curso de Engenharia de Transportes, da UFG.

${ }^{3}$ ONG CRIANÇA SEGURA. Disponível em: https://criancasegura.org.br/dados-de-acidentes/. Acesso em: 12 mar. 2020.

Revista Extensão \& Cidadania, v. 9, n. 16, p. 136-152, jul./dez. 2021.

ISSN 2319-0566 DOI: 10.22481/recuesb.v9i16.9193 
Figura 6 - Logo da campanha "Trânsito com educação, transporte essa ideia"

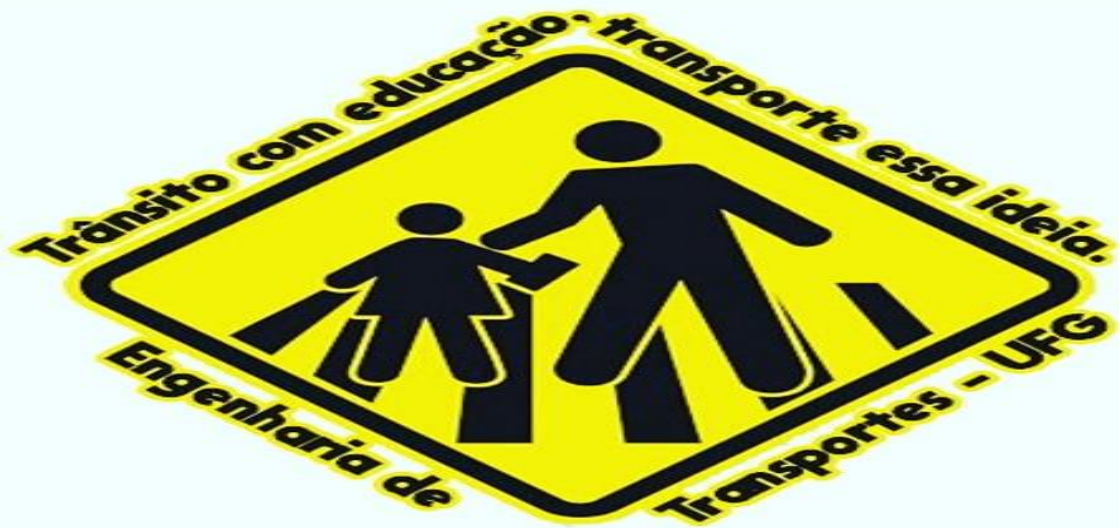

Fonte: Elaborado pelo autor.

Desse modo, no dia 18 de setembro de 2019, os estudantes acompanharam a Marcha pela Vida proposta pela Prefeitura do Município de Aparecida de Goiânia (Figura 6), o evento percorreu ruas da cidade e concentrou as ações na praça central. $\mathrm{Na}$ oportunidade, os participantes conheceram o curso de Engenharia de Transportes, pois mesmo os servidores da prefeitura informaram desconhecer a existência desse curso no município.

No dia 25 de setembro de 2019, os estudantes mais uma vez foram para as ruas, dessa vez, realizou-se uma blitz educativa com distribuição de panfletos. No dia 18 de fevereiro de 2020, o bolsista do projeto de extensão acompanhou outra blitz com fins educacionais.

Figura 6 - Blitz educativa com distribuição de panfletos no Bairro Garavelo, Aparecida de Goiânia

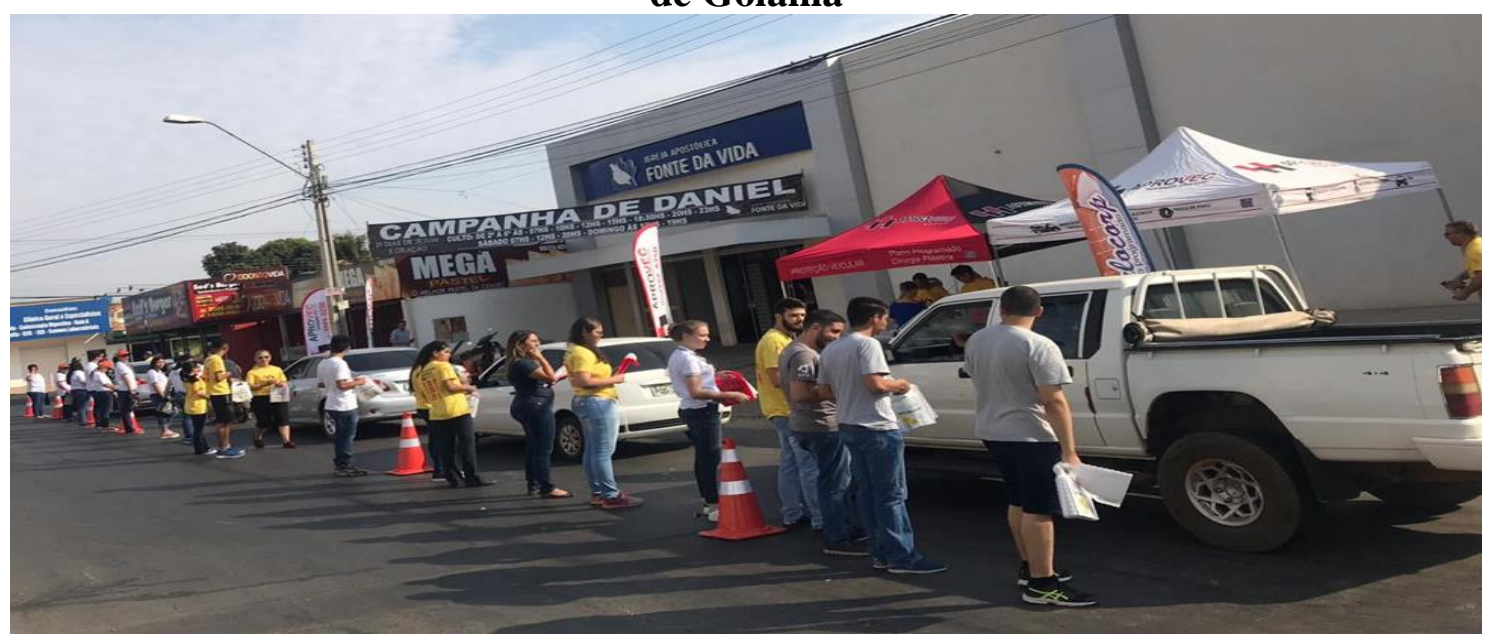

Fonte: Elaborado pelo autor.

Revista Extensão \& Cidadania, v. 9, n. 16, p. 136-152, jul./dez. 2021. 
Além do exposto, todas as ações foram mediadas por uma discussão sobre a importância dessas atividades, e ao mesmo tempo, a dificuldade de se mensurar sua eficiência, pois os participantes passam e não se pode avaliar as suas percepções.

Ao final das atividades de ensino, realizou-se uma avaliação da disciplina, utilizou-se da avaliação institucional disponibilizada pela UFG, como referido. O componente curricular foi qualificado por 7 estudantes com nota 9,71, os discentes costumam examinar 10 critérios. Da avaliação elaborada pelo responsável pela disciplina, 17 acadêmicos responderam ao questionário proposto.

Assim, quando inquiridos sobre o aprendizado mais significativo da disciplina, a resposta mais recorrente foi "ampliação da visão sobre educação para o trânsito", com $20 \%$ das respostas, 94,1\% avaliaram o modo de condução das aulas como totalmente adequado. As respostas foram motivadas pelo fato de que o componente curricular foi orientado para atividades práticas $(88,2 \%$ dos inquiridos).

As ações que mais agradaram aos estudantes foram aquelas realizadas em escolas, revelaram que a disciplina contribuiu para ampliar o conhecimento de profissionais fora da universidade. Portanto, cumprindo o papel de divulgar as ações universitárias e, ao mesmo tempo, compreender o que os órgãos externos estão propondo para pensar ações de educação para o trânsito.

\section{Considerações finais}

A partir dos resultados, ficou evidente que a extensão universitária, por meio de atividades práticas junto à sociedade, contribui para sua curricularização, um benefício para o curso de Engenharia de Transportes, da UFG. Além da ação de extensão trazer benefícios aos estudantes e professores da graduação, os estudantes tiveram a oportunidade para a realização de trabalhos de inserção social e apresentaram entusiasmo, revelando produtos valiosos que podem ser exaustivamente analisados numa perspectiva científica, pois gerou conhecimento. Inclusive, quatro estudantes publicaram um artigo numa revista de extensão, disponível em Sousa et al. (2020). Os professores do curso de Engenharia de Transportes foram beneficiados, pois a maioria não tinha experiência com extensão universitária.

Destaca-se ainda os benefícios para estudantes e docentes das escolas públicas participantes. Os docentes receberam dados e informações valiosos que podem ser utilizadas

Revista Extensão \& Cidadania, v. 9, n. 16, p. 136-152, jul./dez. 2021. 
nas suas práticas de ensino, os estudantes foram incentivados a pensar o trânsito, intervir de forma ativa, tomando consciência dos perigos à vida. Observou-se ainda que as crianças reportaram aos comportamentos inadequados dos pais/mães e responsáveis no trânsito, portanto, foi possível estabelecer um diálogo interativo por meio das ações do projeto de extensão, especialmente pela escuta. Assim, a partir do projeto, esperamos que as crianças e jovens atuem como "fiscais" para boas práticas no trânsito.

Por fim, as atividades práticas, por imersão no objeto de estudo, é outro benefício, por contribuírem para que os estudantes do curso de Engenharia de Transportes julgassem que a disciplina favoreceu a produção autônoma. Isso é importante, visto que uma das atribuições da engenharia é atuar na educação para o trânsito.

\section{Referências}

BRASIL. Resolução nº. 7, de 18 de dezembro de 2018. Diretrizes para a Extensão na Educação Superior Brasileira. Brasília, DF, 2018.

BRASIL. Lei ${ }^{\circ}$. 13.005, de 25 de junho de 2014. Aprova o Plano Nacional de Educação PNE e dá outras providências. Brasília, DF, 2014.

BRASIL. Lei no . 10.172, de 9 de janeiro de 2001. Aprova o Plano Nacional de Educação e dá outras providências. Brasília, DF, 2001.

BRASIL. Lei nº . 4.024, de 20 de dezembro de 1961. Fixa as Diretrizes e Bases da Educação Nacional. Brasília, DF, 1961.

CHAER, G.; DINIZ, R. R. P.; RIBEIRO, E. A. A técnica do questionário na pesquisa educacional. Evidência, v. 7, n. 7, p. 251-266, 2011.

CAMPOS, C. I.; RAIA JUNIOR, A. A. Mortalidade de crianças de 0 a 14 anos em decorrência de acidentes de trânsito no Brasil. XXVII Associação Nacional de Pesquisa e Ensino em Transportes - ANPET. Anais [...]. Belém, 2013, p. 1-14.

COELHO, G. C. A extensão universitária e sua inserção curricular. Interfaces - Revista de Extensão da UFMG, v. 5, n. 2, p. 5-20, 2017.

GLENDON, A. I. Neuroscience and Young Drivers. Handbook of Traffic Psychology, v. 1, p. 109-125, 2011.

Revista Extensão \& Cidadania, v. 9, n. 16, p. 136-152, jul./dez. 2021.

ISSN 2319-0566 DOI: 10.22481/recuesb.v9i16.9193 
LIMA, R. T. Classificação de Campanhas Educativas de Trânsito. 79 f. (Pós-graduação em Gestão, Educação e Segurança no trânsito) - Universidade Cândido Mendes, Rio de Janeiro, 2009.

MAOSKI, F. Trânsito e Educação. In: BIANCHI, A. Projetos de Educação para o Trânsito. Curitiba: CRV, 2015.

MARTINS, J. P. A educação de trânsito: campanhas educativas nas escolas. Belo Horizonte: Autêntica, 2004.

POLÍTICA NACIONAL DE EXTENSÃO UNIVERSITÁRIA. Fórum de Pró-Reitores das Instituições Públicas de Educação Superior Brasileiras. Manaus, 2012.

ROZESTRATEN, R. J. A. Psicologia do trânsito: conceitos e processos básicos. São Paulo: E.P.U, 1988.

SANTOS, W. B. ABC da Municipalização do Trânsito. Pernambuco: Livro Rápido, 2005.

SANTOS, A.; MATINELI, G.; VILARINHO, M.; BARROS, J. "A Universidade vai à escola": Relatos de uma Experiência de Extensão Universitária em Cartografia. Revista de Cultura e Extensão, v. 19, p. 91-105, 2018.

SANTOS, A. M. Educação para o Trânsito na escola: relato de uma experiência pedagógica a partir da extensão universitária. Revista Diálogos, v. 22, n. 1, p. 19-34, 2019.

SANTOS, A. M.; FRANCO, T. F.; FARIAS, T. S. S.; SOUZA, D. L. L. "Aprender fazendo" cartografias: relato de experiência através da extensão universitária. Revista Conexão UEPG, v. 16, p. 1-13, 2020.

SANTOS, A. M. (org.). Ações na escola para educação e segurança no trânsito [E-book]. Goiânia: [s.n.], 2021.

SOUSA, J. P. B. et al. Trânsito e educação: Relato de uma experiência no ensino fundamental, no município de Aparecida de Goiânia, Goiás. Cataventos - Revista de Extensão da Universidade de Cruz Alta, v. 12, n. 1, p. 37-53, 2020.

Recebido: 28.06.2021

Aceito: 05.09.2021

This work is licensed under a Creative Commons Attribution 4.0 International License.

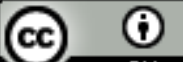

Internacional.

Este trabalho está licenciado com uma Licença Creative Commons - Atribuição 4.0

Revista Extensão \& Cidadania, v. 9, n. 16, p. 136-152, jul./dez. 2021.

ISSN 2319-0566 DOI: 10.22481/recuesb.v9i16.9193 